\title{
Lessons Learned in the High-Speed Aerodynamic Research Programs of the NACA/NASA
}

\author{
M. Leroy Spearman* \\ NASA Langley Research Center \\ Hampton, Virginia 23681
}

\begin{abstract}
I. Abstract
The achievement of flight with manned, powered, heavier-than-air aircraft in 1903 marked the beginning of a new era in the means of transportation. A special advantage for aircraft was in speed. However, when an aircraft penetrates the air at very high speeds, the disturbed air is compressed and there are changes in the density, pressure and temperature of the air. These compressibility effects change the aerodynamic characteristics of an aircraft and introduce problems in drag, stability and control. Many aircraft designed in the post-World War II era were plagued with the effects of compressibility. Accordingly, the study of the aerodynamic behavior of aircraft, spacecraft and missiles at high-speed became a major part of the research activity of the NACA/NASA. The intent of the research was to determine the causes and provide some solutions for the aerodynamic problems resulting from the effects of compressibility. The purpose of this paper is to review some of the high-speed aerodynamic research work conducted at the Langley Research Center from the viewpoint of the author who has been active in much of the effort.
\end{abstract}

\section{Introduction}

Compared to surface-based forms of transportation, a major feature of flight is in speed and access to space. The Wright Brothers flight in 1903 achieved an airspeed of about $31 \mathrm{mph}$. The means of propulsion developed by the Wright Brothers consisted of a propeller (or airscrew) that was rotated by an internal combustion reciprocating engine Such a propulsion system remained the primary power plant for aircraft for the next 4 decades. Advances in materials and structures and in aircraft design made it possible to progressively increase the speed of aircraft. Theses advances included such things as cantilevered monoplane wings, retractable landing gears, and engine cowlings. Increasing the rotational speed of the propeller could increase the thrust provided by a propeller but the rotational speed became limited by the compressibility of the air. Further increases in thrust came through the use of reaction type systems such as rockets and turbojet engines. Before the century was half over, airplanes equipped with reaction propulsion systems were capable of flying at speeds greater than the speed of sound and at the speed required to gain access to space.

\section{Discussion}

High-speed aerodynamic research was initiated at NACA in 1927. Some early blow-down type tunnels at Langley provided short duration runs at speeds up to a Mach number of about 1 . These tunnels led the way to early tests of airfoil shapes designed for high-speed flight. Airfoil shapes that were developed were to be used in airplanes being designed for use in World War II. The North American P-51, for example, made use of the newly developed NACA laminar-flow airfoil section. Other NACA research prior to World War II resulted in progressive increases in aircraft speed up to the point where some effects of compressibility were experienced by high-speed propeller-driven airplanes such as the Lockheed P-38 , the Republic P-47 and the North American P-51. The changes in pressure distribution and the formation of local shock waves affected the stability level, the control effectiveness, and the maximum speed. Further advances in speed were promoted near the end of World War II. Developments by both the Germans and the British led to the use of jet and rocket propulsion. German research indicated that the use of wings with swept or delta planforms were desirable for high-speed flight.

Among the first tests of various wing planforms in the U.S. were conducted by the author in 1945 in the Langley 7- by 10-foot Atmospheric Wind Tunnel (AWT). The basic aerodynamic characteristics of the 
wings were measured as well as the downwash characteristics aft of the wings. The tests were extended to larger scale models in 1947 with test in the new Langley 300-mph 7-by 10-foot tunnel. The use of a swept wing was adopted by North American in late 1945 for what was to become the F-86. The design, which originally had a straight wing, became the first American swept-wing fighter when it flew in 1947.

The use of swept wings was beneficial for high-speed flight but did introduce some low speed problems related, in particular, to the attainment of high lift. It was thought logical to combine the desirable characteristics of low sweep and high sweep into a variable wing-sweep concept. This gave rise to a considerable amount of research in the aerodynamics and the structure of variable sweep designs. Some of the resulting aircraft were the F-111, the F-14 and the B-1.

Other tests in which the author was involved at the new Langley High-Speed 7-by10 foot tunnel were those associated with the transonic bump technique in 1946. The transonic bump was a large wooden block attached to the test section floor. The block had an airfoil contour over which the airstream was accelerated to transonic speeds even though the main tunnel airstream was subsonic. Although relatively crude, the transonic bump was used to provide some of the first transonic data for small models mounted in the flow field over the bump. Several research models tested with the transonic bump provided insight into the aerodynamic problems that would be faced in the transition from subsonic to supersonic flight. Most troublesome initially was the compressibility of the air as the speed of sound was approached. This compression of the air caused the formation of shock waves and substantial increases in drag. The increase in transonic drag seemed insurmountable for some shapes and gave rise to what was termed as the sound barrier. Some of the models that were tested included those representative of the coming Bell X-1 and X-2 experimental research airplanes. The X-1 became the first airplane to break the sound barrier in October 1947. The successful break through the sound barrier was not due to any low drag feature, however, but was accomplished through the use of a powerful rocket propulsion system. The duration of flight and the range was quite low. In addition to the drag rise characteristic, another phenomena demonstrated by the transonic bump tests was the increase in longitudinal stability through the transonic range. Such an increase in stability would tend to add to the problems of drag due to trimming at supersonic speeds. This increase in stability was associated with a rearward shift in the wing aerodynamic center, changes in the effective downwash for aft tail locations, and the rearward shift of wing carry-over lift to the afterbody.

Other methods for obtaining transonic data at NACA-Langley in the mid 1940's included free-fall drop models, free-flight rocket-propelled models, and the wing-flow technique which was similar to the wind tunnel transonic bump system. These methods were soon to be followed by the X-series of flight research airplanes. The X-series of research airplanes was initiated by NACA in the 1943-1944 time period. The initial airplanes were to include thin wings, swept wings, and low-aspect-ratio wings. Both rocket and jet propulsion were to be considered. The Air Force, working with Bell, was to handle thin wings and wing sweep. The Navy, working with Douglas, was to handle low-aspect-ratio and wing sweep. The initial concepts were the Bell XS-1 and the Bell XS-2 (subsequently the "S" was dropped), the Douglas D-558-I and D-558-II, and the Douglas X-3. The X series of airplanes continued to grow and include such things as wing planform, variable wing-sweep, and, with the North American X-15, hypersonic flight. Large-scale, slotted-throat transonic tunnels were being developed at NACA-Langley under the direction of John Stack. The converted Langley 8-foot transonic tunnel was operational in December 1949 , followed a year later by the Langley 16-foot transonic tunnel.

Some small supersonic tunnels were operational in the mid-1940's. Tests of a very small model of the Bell X-2 were undertaken in the Langley 9-inch supersonic tunnel in 1945. The first large supersonic tunnel at Langley, the 4-foot supersonic pressure tunnel (4-Ft.SPT), became operational in 1948. The author, having gained some experience with the transonic bump, was transferred to the new tunnel. The first test to be conducted was for a relatively large-scale model of the X-2. Other research airplanes that were to be investigated in the 4-ft SPT were the Douglas D-558-I and D-558 II and the North American X-15.

In the early 1950's some supersonic aerodynamic research was begun that was related to missile systems. This research was prompted by a problem that had occurred with the U.S. Nike Ajax surface-to-air missile. 
The missile would tumble out of control at high altitudes and a Mach number of about 2. A model was designed and built by NACA and tested in the Langley 4-Ft. SPT at a Mach number of 2.01. The tests indicated that the tumbling was the result of a pitch-up instability caused by the increase in forebody lift for the high length-to-diameter ratio body. This marked the beginning of extensive research into a study of the factors affecting the aerodynamic characteristic of missiles

In the mid 1950's a series of general research models were investigated with the hope that the information could be used as a guide in the design of new aircraft and missiles. The models included variations in body geometry, wing geometry and location, tail geometry and location, control systems and so on. Among the generic models was one dedicated to the study of forward tails or canards. Little information was available for such designs in the time period that the B-70 was conceived. Other tests were being conducted for various specific airplane and missile concepts. These included most all of the century series airplanes as well as the F11F, F4, SR-71, B-58 and others. Most of these airplanes experienced some stability and control problems, but corrective measures were applied with experimentally developed fixes.

One of the problems was generally inadequate directional stability at supersonic speeds. Contributing factors to this problem included the variation of the vertical tail lift curve slope with Mach number; the location of the center of gravity; and interference flow fields. The decrease in lift curve slope that comes with increasing Mach number results in a decrease in the side force provided by the tail in sideslip. The center of gravity is often far rearward due to the jet engine location and this reduces the moment arm to the tail center of pressure and thus the restoring yawing moment. In addition, the far aft center of gravity location increases the instability of the body in sideslip. Interference flow fields that might be caused by the wing/body combination can sometimes affect the efficiency of the vertical tall. These conditions often lead to an instability level for the wing-body combination that exceeded the restorative power of even an efficient vertical tail. Fixes to this problem were generally provided through an increase in vertical tail area and the addition of ventral fins. In some cases, small span strakes were placed near the nose of the body. These strakes would disrupt the flow over the forebody at high angles of attack and sideslip and reduce the destabilizing sideforce. The concern for directional stability soon led to the use of twin vertical tails with airplanes such as the B-70, F-14, F-15 and F-18, for example.

In the case of the Convair F-102 airplane, some very extensive modifications were required. The original airplane was intended to be a supersonic air defense fighter but it was found to be incapable of penetrating the sound barrier because of the high transonic drag rise. Production of the airplane was stopped while a solution to the drag rise problem was sought. This led to the application of the newly developed transonic area rule. The area rule concept is based on a fundamental problem associated with compressibility that, simply stated, says that the drag of a shape moving through the air is directly related to the extent of the disturbance imparted to the air. Thus the cross-sectional area of an airplane should vary as smoothly as possible from the front to the back. The ideal shape would be as nearly parabolic and slender as possible. The extra cross-sectional area caused by the addition of a wing to a body should be compensated for by the removal of some area from the body. Such a modification to the F-102 shape was experimentally verified in tests in the Langley 8-foot transonic tunnel. The appearance of such contouring gave rise to terms such as 'coke-bottle' or 'wasp-waist' designs. It is not necessary that for transonic flight an airplane should have a 'coke bottle' shape. It is only necessary that the area or volume distribution be smooth and this can be accomplished by various means such as careful placing of components, shaping of planforms, selection of airfoils and so on. The use of the area rule resulted in the return to flight for the F-102. However, other modifications made to the design that involved such things as the wing camber shape, the vertical tail planform, and the propulsion system resulted in an essentially new airplane that became the F-106. The concept of the area rule was applied to the F-106 as well as to many other high-speed aircraft designs.

Some early supersonic designs revealed some problems of inadequate aerodynamic control. Trailing edge flap controls often experienced a loss in effectiveness due to shock-induced separated flow. This condition was relieved in some cases by reducing the surface slope at the control and creating a blunt trailing edge. Such a blunt trailing edge can be seen on the X-15, for example. However, flap type controls were soon to be eliminated and the all-moving differentially deflectable tail was to be used for pitch and roll control. 
A new phenomena encountered with supersonic flight was the change in local dynamic pressure fields that may occur for lifting wings or bodies at an angle of attack. In the upper surface flow field (expansion), the local dynamic pressure is substantially reduced. On the underside of the surface (compression) there is a significant increase in local dynamic pressure. Not only do these local dynamic pressure changes affect the lifting surface itself, but also the characteristics of any other part of the vehicle located in the flow fields induced downstream. The effectiveness of an aft tail could be seriously impaired if located in the upper surface flow field or considerably enhanced if located in the lower surface flow field.

A lateral stability characteristic that was found to be related to supersonic flight was the variation of effective dihedral with angle of attack. The effective dihedral is defined as the rolling moment due to sideslip and is considered favorable when the leading wing panel in sideslip tends to rise so as to bank the aircraft into a turn. Such a tendency generally exists at subsonic speeds since the leading wing in sideslip has a greater lift curve slope than the more highly swept trailing wing. This condition was found to be reversed at supersonic speeds when the leading wing became sonic and experienced a decrease in lift curve slope. Thus the roll-to-sideslip ratio became a function of Mach number.

When the propeller became a limiting factor to increased speed, a considerable amount of research was conducted from the 1930's to the mid-1950's in an effort to develop a high-speed propeller The research was done in several wind tunnels as well as in flight but the use of high-speed propellers was never adopted. The solution for the propulsion of high-speed aircraft was to come with the introduction of reaction propulsion systems. Rocket and jet propulsion systems were developed to operational status in Germany for both aircraft and missiles before the end of World War II. Some work had also been done with jet propulsion by Whittle in England. Goddard did early work on rocket propulsion in the U.S. The first American jet-propelled airplane was the Bell P-59 Airacomet powered by two General Motors engines that were based on a Whittle design. The P-59 was under secret development in the early 1940's and first flew on October 1, 1942. The P-59 had twin jet engines mounted near the wing root section. The arrangement resulted in a swaying motion in flight due to slight variations in the jet flow from the twin nozzles. The P-59 was considered unsuitable as an operational fighter but was relegated to a training role for jet pilots. Bell considered a single engine version of the P-59 but subsequently relinquished the project to Lockheed. Lockheed proceeded to develop the single-engine P-80 that became the first U.S jet fighter.

The introduction of jet propulsion systems gave rise to other considerations. For example, the mass distribution was generally quite different from that for reciprocal engine designs. The typical reciprocal engine-propeller arrangement was located forward and resulted in a forward location of the center of gravity (c.g.). Jet engines, however, were placed near the mid-body or aft portion of the airframe and resulted in a more aft c.g. location. Thus, those force and moment factors that are related to the c.g. location would be influenced. The forebody lift will produce a destabilizing pitching moment with increasing angle of attack and the forebody sideforce will produce a destabilizing yawing moment with increasing angle of sideslip.

Another consideration would be the direction of the jet flow as it exits the nozzle. For example, the McDonnell F-101 and the McDonnell F-4 each had twin nozzles located low on the body just aft of the wing and forward of the tail. To minimize the effects of the jet flow on the horizontal tail, the F-101 had a high T-tail arrangement so that the jet flow would pass below the tail. The F-4 used a high degree of negative dihedral (anhedral) in the horizontal tail so that, with increasing angle of attack, the tail was gradually immersed in the jet flow.

The first jet fighter designed in the U.S. following World War II was the Republic P-84. The P-84 was a straight-wing, single jet design similar to the P-80. The original design submitted to NACA-Langley for wind tunnel tests had a curved jet exit that carried the graceful lines of the vertical tail on to the body. Much to the displeasure of Alexander Kartveli, the chief designer of Republic, it was necessary to disrupt the graceful lines by making a flat base at the rear of the body so that the jet would not be deflected. It is interesting to note that further modifications to the airplane resulted in the application of a swept wing and tail and an all-moving tail for control.

American Institute of Aeronautics and Astronautics 
The knowledge gained in the high-speed aerodynamic research programs of NACA/NASA has been used in many military aircraft research and development programs. Such programs have included:

o TAC - A program to develop an airframe to meet Air Force requirements of the Tactical Air Command. The requirements included low-altitude supersonic penetration; long range; and short field takeoff and landing. capability

o TFX - Tactical Fighter Experimental. A program intended to provide a common airframe that could be used by the Air Force, Navy and Army. The program utilized thousands of hours of wind-tunnel time and manpower time from NASA.

o CAP - A program to develop a combat air patrol aircraft for the U.S. Navy. The aircraft should be aircraft-carrier compatible and should have long endurance capability.

o SHAPE - A program to develop a NATO fighter for the Supreme Headquarters Allied Powers in Europe. The airplane should be capable of supersonic flight and should have short-field take-off and landing capability.

o LFAX - A programs to aid in the development of an Air Force fighter aircraft to replace the Century series of fighters. This resulted in the McDonnell F-15 airplane.

o VFAX - A program directed toward the Navy requirement for a new fighter aircraft compatible with operation from an aircraft carrier This resulted in the Grumman F-14 airplane.

o LWF - A research program dedicated toward the development of a lightweight fighter airplane. This program resulted in the General Dynamics F-16 for the Air Force and the McDonnell Douglas F/A-18 for the Navy.

The research effort in supersonic aerodynamics was directed toward civil aircraft in the 1950's. The concept for a supersonic transport (SST) was to increase productivity through higher speed cruise flight while maintaining safe low speed flight. The research program for the supersonic commercial air transport (SCAT) began in 1959. Over a period of about 7 years a total of 40 configurations were investigated. NASA research engineers primarily conceived the designs. Tests were made at subsonic, transonic and supersonic speeds for the most promising designs. In February 1963 four of the concepts were selected for more detailed study under a contract with Lockheed and Boeing. In June 1963, a national SST program was announced. The FAA awarded a contract to Boeing in December 1966 to develop the first U.S. supersonic transport. The design was plagued with weight and stability problems. With these technical problems coupled with economic, political and ecological problems, the U.S. SST program was cancelled in March1971. The NASA research effort to develop an acceptable supersonic transport airplane continued in 1972 under the name Advanced Supersonic Technology (AST). Critics of the SST program took AST to mean "advanced supersonic transport" so the name was changed in 1974 to be Supersonic Cruise Aircraft Research (SCAR). In 1976 the name was changed to Supersonic Cruise Research (SCR) to clearly indicate that it was a research program and not an aircraft program.. The SCR program was cancelled in 1982 due, in part, to budget constraints. In 1987 a renewed emphasis in supersonic cruise research was undertaken in the High Speed Civil Transport (HSCT) program office but this office has now been disbanded.

Other areas of interest have had an impact on high-speed aerodynamic research. One of these areas involved the study of various foreign aircraft and missile systems. Much was learned from these studies and it was clear that other countries had learned much from NASA research. Another area of research that has benefited from previous high-speed research programs is that related to the development of spacecraft.

\section{Epilogue}

The achievement of high-speed flight with aircraft, spacecraft and missiles became a reality in the early 1940's when rocket and jet propulsion systems came into use. Advancements in aeronautical research were then accelerated by the NACA/NASA in order to meet challenges of high-speed flight vehicles. There has been a substantial amount of high-speed research applied to military systems while the application to civil aircraft has been limited. And now, just as the propulsion change from propellers to rockets and jets brought in a new era of supersonic vehicles, the successful development of the scramjet engine may result in a new era of hypersonic vehicles.

American Institute of Aeronautics and Astronautics 


\section{Bibliography}

Spearman, M. Leroy: Some Aviation Growth Events. AIAA Paper 2002- 0172, Presented at the AIAA 40th Aerospace Sciences Meeting, Reno, NV Jan.14-17, 2002

Spearman, M. Leroy: A Review of 50 Years of Aerodynamic Research with NACA/NASA. NASA TM 109163,1994.

Spearman, M. Leroy: The Evolution of the High-Speed Civil Transport. NASA TM 109089, 1994.

Spearman, M. Leroy: Historical Trend in the Research and Development of Aircraft. NASA TM 84665, 1983.

Spearman. M. Leroy: Historical Development Of Worldwide Supersonic Aircraft. NASA TM 85637, 1983.

Spearman, M. Leroy: Design Trends for Army /Air Force Airplanes in the United States. NASA TM 4179, 1990.

Spearman, M. Leroy: Before the High-Speed Civil Transport. Presented at the AIAA/AHS/ASEE Aircraft Design, Systems and Operations Conference, Seattle, Washington July 31-August 2, 1989.

Spearman, M. Leroy: Some Aerodynamic Discoveries and Related NACA/NASA Research Programs Following World War II. NASA TM 86258, 1984.

Ellis, Paul: Aircraft of the U.S.A.F., Sixty Years In Pictures. Jane's Publishing Co. London 1980.

Fifty Years of Aeronautical Research. National Aeronautics and Space Administration. Washington, D.C. 20546, 1967.

Sixty Years of Aeronautical Research 1917-1977. National Aeronautics and Space Administration. Washington D.C. 20546, 1977.

Baals, Donald D. and Corliss, William R. : Wind Tunnels of the NASA. NASA SP-440, 1981.

Schultz, James: Winds of Change. Expanding The Frontiers of Flight, Langley Research Center's 75 Years of Accomplishment, 1917-1992. National Aeronautics and SpaceAdministration, Washington,D.C.20546, 1992.

Jones, Lloyd S.: U.S. Fighters. Aero Publishers, Inc. 1975.

Knaack, Marcelle Size: Encyclopedia of U.S. Air Force Aircraft and Missile Systems. Volume I. Post-World War II Fighters, 1945-1973. Office of Air Force History, Washington, D.C. .1978.

Angelucci, Enzo and Matricardi, Paolo: World Aircraft, Military, 1945-1960. Rand McNally \&Company, Chicago, Illinois 1978.

Office of TAC History: Aircraft of Langley AFB, 1917-1977. Headquarters Tactical Air Command

Gunston, Bill: Aviation, The Complete Story of Man's Conquest of the Air. Octopus Books Limited, London, 1978. 
Becker, John V.: The High-Speed Frontier. Case Histories of Four NACA Programs, 1920-1950. NASA SP-445, 1980.

Reithmaier, Larry: Mach 1 and Beyond, The Illustrated Guide to High-Speed Flight. TAB Books. a Division of McGraw-Hill, Inc.,1995.

Smith, H.C."Skip": The Illustrated Guide to Aerodynamics, 2nd.Edition. TAB Books. a Division Of McGraw-Hill, Inc.,1992.

Heppenheimer, T.A.: Scramjets that will reach Mach 25. Popular Science, April 1986, page 94. 